\title{
Restraints as a Mechanic for Bodily Play
}

Matjeka, Louise Petersen; Hobye, Mads; Larsen, Henrik Svarrer

Published in:

CHI 2021 - Proceedings of the $2021 \mathrm{CHI}$ Conference on Human Factors in Computing Systems

DOI:

$10.1145 / 3411764.3445622$

Publication date:

2021

Document Version

Early version, also known as pre-print

Citation for published version (APA):

Matjeka, L. P., Hobye, M., \& Larsen, H. S. (2021). Restraints as a Mechanic for Bodily Play. In CHI 2021 -

Proceedings of the $2021 \mathrm{CHI}$ Conference on Human Factors in Computing Systems: Making Waves, Combining Strengths (pp. 1-14). [441] Association for Computing Machinery. https://doi.org/10.1145/3411764.3445622

\section{General rights}

Copyright and moral rights for the publications made accessible in the public portal are retained by the authors and/or other copyright owners and it is a condition of accessing publications that users recognise and abide by the legal requirements associated with these rights.

- Users may download and print one copy of any publication from the public portal for the purpose of private study or research.

- You may not further distribute the material or use it for any profit-making activity or commercial gain.

- You may freely distribute the URL identifying the publication in the public portal.

Take down policy

If you believe that this document breaches copyright please contact rucforsk@kb.dk providing details, and we will remove access to the work immediately and investigate your claim. 


\section{Restraints as a Mechanic for Bodily Play}

\section{LOUISE PETERSEN MATJEKA}

Computer Science, Norwegian University of Science and Technology - NTNU, Trondheim, Norway

louise.matjeka@ntnu.no

MADS HØBYE

Computer Science, Roskilde University - RUC, Denmark, mads@hobye.dk

HENRIK SVARRER LARSEN

K3/School of Arts and Communication, Malmö University, Sweden, henrik.svarrer.larsen@mau.se

This paper presents restraints - directly imposed restrictions on players' bodily movements, as a mechanic for bodily play in HCI. While this is a familiar mechanic in non-digital movement-based games, its potential in designing bodily play experiences in $\mathrm{HCI}$ has been scarcely explored. Three types of restraints observed in non-digital movement-based games, are explored here: fixating body parts, excluding body parts and depriving/manipulating bodily senses. Then, we investigate the experiential dynamics of restraints as a bodily play mechanic bridging a phenomenological perspective on bodily movement with theories on play. These investigations form the theoretical framework for the subsequent analysis of five digital body game examples. Building on this analysis and theoretical framework, we formulate five design strategies for implementing restraints as a mechanic for bodily play in HCI. We propose restraints as a generative resource for researchers and designers interested in understanding and designing bodily play experiences in $\mathrm{HCI}$.

CCS CONCEPTS • Human-centered computing Interaction design theory, concepts and paradigms • Humancentered computing $\sim \mathrm{HCI}$ design and evaluation methods

Additional Keywords and Phrases: Bodily Play, Game Design, Bodily Play Experiences, Phenomenology, Restraints, Movement-Based Games, Body Games, Interaction Design

ACM Reference Format:

\section{INTRODUCTION}

Designing for bodily play and playful movement in HCI is increasingly gaining traction $[3,6,7,19,31,36,45,46,48,57]$ together with the development of tools, guidelines, lenses, and tactics facilitating such body-centric experiences, i.e., body games, movement-based games, or exergames $[8,56,62,78]$. However, movement-based games and bodily play have existed long before digital games were invented and can officially, at least, be traced as far back as the ancient Olympic Games [89]. Over time, movement-based games have grown in popularity, with competitions conducted all over the world. Movement-based games have, for example, been used to determine hierarchies among young men in 19th-century villages [54] or as Deterding [16] pinpoints, as alibis for adult play nowadays. Furthermore, play scholars share the opinion that play is fundamental to human civilization, social life, and personal development $[5,11,21,30,32,54,76]$. We will refer to this comprehensive tradition of movement-based games and bodily play experiences as non-digital movement-based games, ranging from sports to social games and play [5,11,20,21,30,32,54,71,75]. By drawing on this tradition of non-digital movement-based games, it is believed that new knowledge can be infused into the digital design 
tradition and can advance the field of designing for bodily play and playful movement in HCI. Concretely, we are interested in bodily play experiences in movement-based games and, particularly, in designing for such experiences in HCI. Building on this tradition of non-digital movement-based games, we investigate the construction of bodily play mechanics in a suite of traditional European games from a phenomenological perspective.

Mechanics in games work to craft the game's specific structure and gameplay [64]. Sicart [70] defines (game) mechanics as "methods invoked by agents, designed for interaction with the game state", where agents comprise any element in the game including players, rules, or challenges. In this paper, we investigate the construction of mechanics in traditional movement-based games and carve out the mechanic of restraints - restrictions of the players' freedom of bodily movement - as an element in a body game's specific structure implemented to craft the gameplay through interactions with, and actions in, a game. The mechanic of restricting the players' freedom of bodily movement is widely applied in movement-based games, such as in sports; for example, hands cannot be used to play with the ball in soccer, and the opposite is true for handball, in which the feet cannot be used to play with the ball. In social movement-based games, this mechanic is used with blindfold $[82,84]$, in which players are blindfolded in a game of catch, or balloon dance, with players dancing in pairs holding a balloon between their heads. While there are examples of this mechanic in the digital realm (see, e.g., [8,9,47]), they are still underexploited in digital body-centric games and playful design research. This paper addresses this gap in the literature by introducing restraints as a bodily play mechanic, in the form of restrictions on the players' bodily movement possibilities, and demonstrating how restraints work as a mechanic for bodily play in both digital and non-digital movement-based games. To understand how restraints lead to bodily play, we discuss the dynamics of bodily play theoretically by linking play theories with a bodily experiential perspective. We do so to answer the following questions: In what ways do restraints work to encourage bodily play? How can we design for such experiences with restraints?

To answer these questions, we first introduce a working definition of restraints to guide our investigations of how restraints work practically as a mechanic by dividing them into three types; fixating body parts, excluding body parts or depriving/manipulating bodily senses. We demonstrate the three types of restraints through corresponding movementbased games from the non-digital game tradition. After establishing restraints as a mechanic for bodily play and emphasising bodily play experiences, we theoretically investigate the experiential dynamics of restraints on bodily play by tying together a phenomenological perspective on bodily experience and movement $[49,59,67-69]$ with theories from play and game studies [11,21,30,39,63,75] and theories of Ihde's postphenomneological human-technology relations $[34,35,61]$. These investigations form the theoretical grounds and function as a theoretical framework for the subsequent analysis of five diverse digital movement-based game examples. We further use these examples to highlight five design strategies to implement restraints as a mechanic for bodily play in HCI. We end the paper by discussing restraints as a generative design resource and a mechanic to encourage bodily play experiences and, based on the investigations and analysis in the paper, propose a redefinition of the initial working definition.

We build our investigations on our subjective experience with the presented examples - both digital and non-digital. Based on a phenomenological perspective of bodily play experiences, we used ourselves as subjects [77] as both players and designers to analyse the presented game examples. The collection of traditional games stems from research, which founded the historic games park Gerlev Legepark [91] in Denmark, where most of the games can be played and experienced. As players, we know these games well. The digital game examples are chosen on the basis of a) each game representing a different aspect of restraints in combination with digital design and b) personal experience with the examples as designer (one of the authors) of two of the examples (Space Agent [73] in section 6.4 and Move Maker [47] in section 6.5) and as players of all the examples [23]. To understand how the mechanics affect the experience and 
subsequently formulate the design strategies, we also rely on our craft knowledge as designers [2], contributing a deeper understanding of the underlying dynamics in the designs [22]. Together with the theoretical grounding [11,3335,39,49,59,61,63,66-69,75], these perspectives provide an opportunity for us to understand and analyse how the mechanics influence our bodily play experience in the examples. As the presented examples are chosen within the range of our personal experience, the examples do not represent a full range of digital bodily play but serve as exemplars of the various restraint types, with the strategies as inspiration and further explanation thereof.

We regard restraints within the methodology of bridging concepts [13] because it is theoretically grounded and illuminated through exemplars, and explores the boundaries of restraints throughout the definition, in the extracted design strategies and subsequently in the discussion and final redefinition. The notion of restraints and the three types thereof are proposed as a generative resource for designers and researchers interested in analysing and designing for bodily play and playful movements in HCI.

Before introducing restraints, we present how related research within the HCI literature has addressed designing for bodily (play) experiences in HCI from various angles.

\section{PREVIOUS HCI DESIGN APPROACHES ADDRESSING BODILY PLAY EXPERIENCES}

Byrne et al. [8] explored limiting players' freedom of bodily movement in their work on vertigo games [7,9,10]. They used galvanic vestibular stimulation (GVS) to manipulate the players' vestibular sense and, thus, vertigo. This restrains their freedom of bodily movement. We build on these vertigo investigations as a design resource and extend it to the restraint type of deprivation/manipulation of the bodily senses.

Within the area of designing for bodily play experiences, Mueller et al. [55] unpacks the German words for the body into two notions: Körper, the physiological body, and Leib, the lived body, to demonstrate their interconnectedness. This implies that when we affect the physiological body, we affect the lived body as well. Just as Mueller et al. dissected the bodily play experience into two linguistic notions, so did Matjeka et al. [48] in their conception of "playing a game". Using the Danish language, the authors highlight how the bodily play experience is both about bodily perceptual stimulation as an exploration and experimentation with the bodily senses, which they refer to as at lege (to be bodily playful), while players also experience bodily play as sensations of bodily achievements, as well as testing, acquiring and developing (new) bodily skills. The authors refer to the latter as at spille (to be bodily "gameful") [48]. We build on these understandings of bodily play experiences to develop our notion of restraints as a mechanic for bodily play.

Within the phenomenological understandings of bodily experience in HCI, Loke and Robertson [44] investigate how the use of technology (particularly sensing) can affect body movement and, thereby, the bodily experience. They develop the Moving and Making Strange methodology and highlight how "making movements strange" attracts users' attention to the quality of their movements. Furthermore, Tennent et al. [78] bring forth a perspective to "making moving strange" through sensory misalignment. The authors highlight how sensory misalignment augments bodily perception and awareness of body movement. These studies help us understand the bodily experience in HCI; however, to design for body movement and experience as bodily play experiences, we still need to approach the processes of bodily experience from a game design perspective.

In the field of designing for bodily movement in HCI, Mueller and Isbister [58] developed a suite of guidelines for movement-based games, emphasising the bodily aspects of self-expression, bodily fatigue, and performative qualities. Furthermore, Segura et al. [46] explored the design space of body games in terms of technology, physical space, and social aspects. While Mueller and Isbister [58] and Segura et al. [46] focus on bodily aspects of digital designs related to 
both physical and social space, inspired by these contributions, we explore how practices from the tradition of nondigital movement-based games can inform current design practices of digital movement-based games.

Moen [51,52] explores full-body movement as an interaction modality in her design of "The Body Bug" and investigates how users' freedom of bodily movement is affected by social and contextual factors. Her focus is to liberate people from personal and social limitations that affect their freedom of bodily movement and develop movement literacy. She does so based in dance culture and literature. We approach bodily freedom of movement from an oppositely direction and investigate how imposing restrictions on the players' freedom of bodily movement works as a mechanic to encourage bodily play and movement in playful activities. While Moen [51,52] designs for the pleasure of movement and her design can serve as an example of fixation restraints, she does not articulate this as a particular play form or mechanic, nor does she draw on any play or game theories in this regard. Though we both focus on bodily movement possibilities, we address the topic differently with different results.

On the general level of design methods, design psychologist D. A. Norman developed the notion of physical constraints as part of his design theory in his book, The Design of Everyday Things [60]. In his conception, constraints guide the user to a desired goal by limiting the device's (or design's) range of possible options for interaction into a streamlined use. Such constraints are widely used for interaction design and user experiences [18,24,28,60,63,65]. However, in play, the "use" should not be streamlined: a game without things to explore and obstacles to overcome would not be play $[12,42,75]$. In facilitating bodily play, physical constraints comprise the physical limitations that make some interactions possible and others not, e.g., the limits and divisions of a playfield, the steps, and paths in a board game, the number of buttons available on the controller and the shape, and divisions in general or on a play mat, e.g., in Twister [29]. In this way, constraints determine a range of options in a design from which players can choose. The

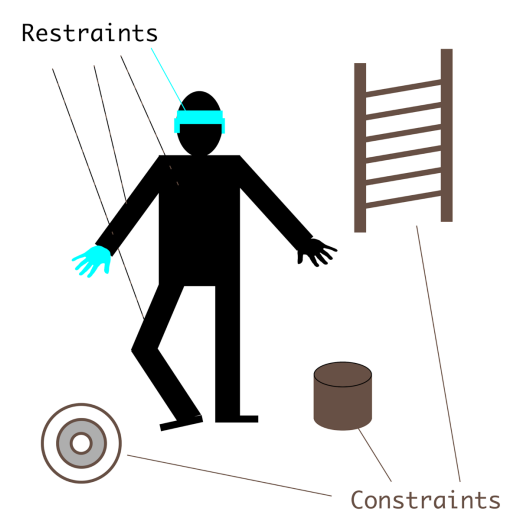

Figure 1: Restraints are limitations of the player's bodily preconditions for (inter)action, while physical constraints are limitations of a design's options for interaction.

players preserve their freedom of movement within these options. Contrarily, restraints are restrictions on bodily preconditions that directly limit the players' freedom of movement (figure 1).

We argue that there is a significant difference between physical constraints (limitations of a design's options for interaction) and restraints (limitations of the player's bodily preconditions for (inter)action; figure 1). The difference lies both in the players' bodily play experience of a design and, as a designer, in how to work with and facilitate bodily play 
in a design. In figure 1, the constraints offer different options for interaction ${ }^{1}$. At the same time, restraints shift the bodily preconditions for interacting with these options: Climbing the ladder constitutes one kind of bodily experience, while climbing the ladder blindfolded or with one arm tied to the back - constitutes another. This paper introduces restraints as a structured way and generative resource for designers and researchers working with bodily play experiences in HCI.

\section{RESTRAINTS}

As previously mentioned, restraints are physical restrictions on the players' capabilities that work to limit the players' bodily freedom of movement in specific ways. To further explore the meaning of restraints, we turn to the linguistic presentation of the word from the Oxford Online Dictionary [86]:

1. The action of keeping someone or something under control [italics by the authors]

2. Deprivation or restriction of personal liberty or freedom of movement [italics by the authors]

3. A device which limits or prevents freedom of movement [86] [italics by the authors]

Following these definitions, we understand restraints as ways to control, restrict, limit, prevent or deprive the players' freedom of bodily movement through actions and devices/technologies - and in games, also through rules (the connection between rules and restraints is further discussed in section 6.6). As such, restraints (re)define the players' bodily preconditions for actions and interactions through rules, actions or devices that affect their freedom of bodily movement and thereby alter their bodily movement possibilities in the game.

Utilising this understanding of restraints as a guiding principle, games with mechanics fitting the above description were singled out. We used the collection of game scholar Møller's 121 traditional European games [53] as the primary source of traditional non-digital movement-based games for this analysis. By searching for common patterns in the restraints across these games, three types of restraints were discovered.

\section{THREE TYPES OF RESTRAINTS}

Through the above-described analysis of the traditional European games [53], the following mechanics that (re)define the players' bodily preconditions for actions and interactions through rules, actions or devices in the games, were singled out: directly fixating or excluding body parts for use in the game, or by depriving bodily senses ${ }^{2}$. These mechanics further led to these three types of restraints:

- $\quad$ Fixating parts of the players' body

- Excluding parts of the players' body

- $\quad$ Depriving or manipulating some of the players' bodily senses

Each type of restraint affects the players' freedom of bodily movement differently. While fixating any of the players' body parts limits the players' freedom of bodily movement, the player is still permitted to use the body part as long as it remains fixated onto where it is supposed to be fixated, e.g., the feet in the pushing game [53] (for further explanation see section 4.1). Contrary, any excluded body parts are excluded; "taken out" of the game, e.g., in a game of soccer,

\footnotetext{
${ }^{1}$ We limit this explanation to contain Norman's physical constraints, while we acknowledge that Norman's notion of physical constraints is rooted in a more extensive discussion of affordances stemming from Gibson's original theory $[25,26]$. Diverging into such a discussion would be out of scope for this paper.

${ }^{2}$ These types of restrictions on bodily preconditions for actions and interactions in movement-based games have previously been explored by Matjeka [47] (for further presentation, see also section 6.5)
} 
fixating the players' feet to each other still allows the players to use their feet (though differently), while their hands are excluded from use (with some exceptions for the goalkeeper and throw-ins). Manipulation of bodily senses was added to the deprivation of bodily senses, since based on the analysis of the games, this mechanic was also found to (temporarily and deliberately) affect the players' freedom of bodily movement, e.g., making people dizzy by turning them around many times.

In the following, the three types of restraints are explored in detail using non-digital movement-based games to illustrate how they work as mechanics for bodily play. While the three types of restraints were initially derived from the analysis of Møller's collection of traditional European games [53], we have chosen to look beyond this pool of games and explain the types of restraints complemented by game examples that are popular nowadays. This is done to aid any reader not familiar with the traditional games to be able to follow the argumentation.

\subsection{Restraints by Fixating Parts of the Players' Body}

Restraints by fixating parts of the players' body are activated when players are either not allowed (as part of the rules) or unable to (as inferred by technology or actions) move a specific body part from a specified place (the floor, the spot, the device, the other player, etc.). A traditional game employing this restraint is the pushing game [53]: Two players fixate their feet to the ground, while holding their hands up in front of their chest, and using only the hands, try to push the other player "off balance". The player who moves his/her foot first loses. To further explain the fixation restraint, we use the newer game, Twister [29].

Twister [29] is a multiplayer non-digital game in which fixation restraints form the core mechanic of the game: One has to fixate a body part on a square on the game's playmat. Which body part to fixate and where to fixate it, is determined by spinning the wheel: the place where the marker on the wheel stops indicates a body part and a colour. The player must then fixate the mentioned body part on a square on the mat matching the indicated colour. In turns, each player follows this process of fixating a body part (that is not already fixated) to the mat. Players can also move an already fixated body part to another square on the mat. This pattern is repeated until a player is unable to overcome the challenge.

\subsection{Restraints by Excluding Parts of the Players' Body}

Restraints by excluding parts of the players' body are found in instances when some body parts are excluded from use either for a specific action in the game or for interaction with a device (such as using the hands to play with the ball in soccer). We explain this restraint type using the universal example of hopscotch [92].

In hopscotch [92], the players' feet are alternately excluded from use in the game. It is a game where players hop through a court divided into different squares: single square, to hop on one foot (the same one foot in all single squares); double square, to place left foot in the left square and the right foot in the right square. To start the game, the players throw a "lucky" (a flat stone, tin can, or "hinkesten"). The player must then avoid the square where the "lucky" lands. Hopscotch is a universal game and exists in many versions [85]. Essential for all versions is that players hop on one foot - with the other foot excluded from use (e.g., not allowed to touch the ground).

\subsection{Restraints by Depriving or Manipulating some of the Players' Body Senses}

Restraints by depriving or manipulating the players' bodily senses are found in instances in which rules, actions or device/technologies are used to deprive a bodily sense (e.g. blindfold, using earmuffs, sunglasses or gloves) or manipulate bodily senses (e.g. the vertigo sense by wearing roller-skates, bicycling, surfing, whirling and turning around). A 
traditional game example of this restraint type is Marc and Luke: While being blindfolded, and with one hand fixated to the edge of a dining table, two players try to catch each other by touching the other player first [53]. This mechanic is similar to the widespread traditional game, blind man's buff [82].

In blind man's buff $[53,82,84]$, the restraint is the deprivation of the catcher's vision. Blind man's buff [82] is an old play form of catch, which has been played for centuries [53]. The core of the game is that the catcher is blindfolded and has to catch one of the other players. All players are restricted a "marked-off space". The catcher can only hear and feel his/her way to the other players. The restraint is the limitation on the vision and, consequently, the alteration of the catcher's bodily perception (no sight, only hearing).

In the above examples, we explained how restraints were instated through rules as in hopscotch (section 4.2), and devices, such as, the blindfold in blind man's buff [82] (section 4.3) and the playmat in Twister [29] (section 4.1). In the following sections, we explain how actions can instate restraints in a game, how restraint types can be combined, and how restraints can change as a game progresses.

\subsection{Restraints through Actions}

Actions from other players often instate restraints. Border Fight [53] is a version of a game of catch in which two teams fight to catch the other team's players. Separated by a border, the players capture the other team's players by dragging them across the border into their territory. The players are not allowed to cross the border otherwise. If they do, they are "caught". The action of dragging another player is an action of fixating the other player with the intention of directly affecting the player's freedom of bodily movement. The player being pulled is most often also trying to pull back to carry the other player into his/her territory. Once a player is "caught" by the other team, the player becomes part of that team.

Other instances where actions from one player instate restraints for other players are games where the players hold on to each other to perform specific actions together, e.g., lap chair [53]: All players form a circle by sitting on the lap of the player behind them (practically the knees). Once they manage to have the lap chair in place (all players "sit" nicely on the player's lap behind), they start to perform other actions together, e.g., "walking" forward or leaning to one side, while singing a song. In the digital game example Move Maker [47] (see section 6.5), we also find restraints by actions: One player can have a restraint, e.g., "left leg glued to another player", thus practically working as a fixation restraint for both players.

\subsection{Temporary Restraints and Combinations of Restraint Types}

As we saw in some of the examples above, restraints can also be temporary and can change during gameplay. In Twister [29] (section 4.1), the restraints are temporary: Once the player has placed both feet and hands on the mat, in the subsequent round, the player can replace a body part of their own choice, however, still corresponding to that indicated by the wheel, hence modifying one of the previous restraints. We present further examples of temporary restraints in the digital game examples Fru game [79] in sections 6.3 and Move Maker [47] in section 6.5. Moreover, just as restraints can be temporary, they can be combined, too.

The game Marc and Luke [53] (section 4.3) provides an example of combining a restraints where a bodily sense is deprived with the restraint of a fixated body part: Both the players are both blindfolded and have one hand fixated to the table while trying to catch each other. While the players have their hands fixated to the table, they can still move around so long as they do not let go of the table with the hand. Twister [29] also has several restraints, though all of them are kind of fixations. We demonstrate more examples of combinations of restraints in the digital game examples presented in section 6 (see, e.g., Fru Game [79] in section 6.3, Space Agent [73] in section 6.4, and Move Maker [47] in 
section 6.5). For now, we continue our definition of restraints and pinpoint some boundaries of restraints and instances in which bodily restrictions do not work as a restraint, but rather as limitations in the surrounding conditions for play.

\subsection{Borderline Cases and Boundaries of Restraints as Restrictions on the Players' Bodily Preconditions}

While restraints are limitations or restrictions of the players' bodily preconditions for actions and interaction, there are borderline instances where the conditions for bodily movement seem restricting and limiting for the players' freedom of bodily movement but do not fully match our description of restraints as fixating or excluding body parts or manipulating or depriving bodily senses. A simple version of hide and seek is an excellent example of a restraint that, on closer analysis, does not fit our definition of restraints as restrictions on the players' bodily preconditions for (inter)action. This is because the catcher might be "restrained" (blindfolded and not allowed to move) at the time of counting, in the beginning of a game (while the other players are hiding), but these are merely instructions in a state of inactivity. The moment the player is allowed to move, and thus act and interact, these restrictions are abolished. As such, a restraint only functions only as a restraint in the instances where the players bodily act or interact. It would have been counted as a restraints if, for instance, the catcher was blindfolded throughout the entire game (and not just when counting) or if the other players' feet were laced up, thereby compromising their ability to move around unnoticed.

There are some versions of hide and seek where the "hiders" are not allowed to change their hide-out when the catcher has finished counting. Though the players' freedom of bodily movement is limited in such instances, the players are not restrained in the form of any body parts being directly fixated or excluded or bodily senses being deprived. We regard such situations as limitations of the surrounding condition resembling a marked-off space instated by rules.

Another borderline case is when the surrounding conditions get so constrained that they (almost) resemble restraints, e.g., passing through a tunnel that is so narrow so that it forces the player to crawl, as found in the exertion escape room example Boda Borg [4]. However, while it is arguable that such conditions affect the players' freedom of bodily movement, they neither fixate nor exclude any body parts from use, nor do they directly deprive or manipulate the body's senses. In this example, it is the surrounding conditions of tight walls limiting the players' space of bodily possibilities. An example of a restraint to encourage players to crawl in this game would be if, e.g., the players' feet were not allowed to touch any of the sides of the tunnel.

We now move on to ground restraints theoretically by linking play theories $[11,39,63,75]$ with phenomenological theories on bodily experience [49,59], and movement [67,68] and technology [34,35,61]. In doing so, we attain a deeper understanding of the experiential dynamics of restraints as a mechanic for bodily play than that presented by the merely practical examples mentioned so far.

\section{THEORETICAL GROUNDING OF RESTRAINTS AS A MECHANIC FOR BODILY PLAY EXPERIENCES}

This section investigates the theoretical grounding of restraints as a mechanic for bodily play experiences. We do so in order to investigate how restraints encourage bodily play experiences by bridging theories of bodily perception and experience in a theoretical play perspective. Concretely, we explore how restraints infer arbitrarily chosen [11] and unnecessary obstacles to overcome [75] which reshuffle our equilibrium [49]. Second, we explain how the obstacles start a process of creating bodily potentialities [59], which for the players emerge as particular spaces of bodily possibilities [63]. We end the section by reviewing bodily play as driven by a desire to experience bodily arousal [39] and kinetic joy rides $[67,68]$ before using these investigations as a framework for the subsequent game analysis. 


\subsection{Restraints Infer Obstacles to Overcome and Reshuffle our Equilibrium}

In play experiences, obstacles function as inferred hindrances, hurdles, or problems that, through interactions, obstructs or deviates the course of the activity. Both Caillois [11] and Suits [75] explain playing as a voluntary quest to overcome obstacles. Caillois [11] describes play as "the pleasure derived from overcoming an arbitrarily chosen obstacle", and Suits [75] describes playing as "a voluntary attempt to overcome unnecessary obstacles" [75]. We argue that restraints create such arbitrarily chosen and unnecessary bodily obstacles.

\subsection{Bodily Experience as a Reshuffling of our Equilibrium}

In our endeavours to link play to a bodily experiential perspective, restraints as bodily obstacles reshuffle the elements of our equilibrium into a bodily play experience. For this argument, we turn to Merleau-Ponty [49], who argues that we pre-reflectively perceive the world through bodily actions: "Whether a system of motor or perceptual powers, our body is not an object for an "I think". It is a grouping of lived-through meanings that moves towards its equilibrium. Sometimes a new cluster of meanings is formed; our former movements are integrated into a fresh motor entity, [...] our natural powers suddenly come together in a richer meaning, which hitherto has been foreshadowed in our perceptual or practical field, [...], and which by its coming suddenly reshuffles the elements of our equilibrium and fulfils our blind expectation" [49]. MerleauPonty [49] here informs us that when we learn or experience new movements, the elements of our equilibrium reshuffle and new meaning arises. It does not require radical changes in our perception to reshuffle the elements of our equilibrium and thereby create new meaning (and play). As Merleau-Ponty [49] describes it, even a little lack of ability can transform the perception of specific actions and initiate a reshuffle. For example, the restraint in Twister [29] (section 4.1) of fixating a body part to the mat and then trying to place another body part on the mat constitutes an obstacle to overcome, creating a little lack in our bodily ability, and, thus, reshuffles the elements of our equilibrium into a bodily play experience. As Merleau-Ponty [49] argues in the quote above, the reshuffling of our equilibrium paves the way for new bodily meaning-making.

\subsection{Bodily Play Experience is Enacted from Potentialities and Creates a New Space of Possibilities}

Bodily perception is the basis for bodily experience and is not something that happens to us but something we enact. Alva Nöe [59] continues Merleau-Ponty's [49] thoughts on bodily perception and argues that perception, and thus experience, entails action. What we choose to enact constitutes our possibilities from a broader range of potentialities. Nöe [59] explains: "Qualities are available in experience as possibilities, as potentialities, but not as completed givens." [59]. Possibilities, as we perceive them, are potentialities interpreted through perception. We form our bodily experiences through interacting with the possibilities available as perceived potentialities. As restraints work to create obstacles that reshuffle the players' equilibrium, new bodily potentialities arise. While playing, the newly formed potentialities constitute a new space of bodily possibilities. In play theory, this space is explained by Salen and Zimmerman [63] as a possibility space: "We call the space of future action implied by a game design the space of possibility. It is the space of all possible actions that might take place in a game, the space of all possible meanings that can emerge from interacting with a game design" [63]. Players constitute their space of (bodily) possibilities through the mechanics offered in a design. Restraints function as such a mechanic.

\subsection{Restraints Stimulate Bodily Arousal and Creates Kinetic Joy Rides}

According to Kerr and Apter's [39] structural-phenomenology of play, players engage in play activities to experience a state of high arousal. Kerr and Apter [39] further explain how play happens in the paratelic state of mind (often referred 
to as the playful state of mind) instead of the telic state of mind, which is associated with seriousness and arousal is perceived as unpleasant. In play, "any form of highly felt emotion will be pleasant, high arousal is pleasant" [39]. Bodily play can create high bodily arousal when players explore a new space of bodily possibilities emerging from their attempts to overcome arbitrarily chosen and unnecessary bodily obstacles. Finally, in our pursuit to understand (some of) the dynamics of bodily play experiences, all these bodily efforts listed so far lead to what Sheets-Johnstone [68] coins as kinetic joy rides.

\subsection{The Bodily Play Experience as Kinetic Joy Rides}

According to Sheets-Johnstone [68], meaningful movement emerges through movements in a kinetic dynamic called kinetic joy rides [67]. Sheets-Johnstone [68] refers to this experience as the synergy of meaningful movements $-\mathrm{a}$ sequence of sensations not felt as separate sensations but as a whole, a process sand an entire experience [68]. She further links such a synergy of movements to play by arguing that movement and play are natural bedfellows and creates the notion of kinetic joy rides [67]. Building on Husserl's phenomenology [33], Sheets-Johnstone [66,67] explains that the players' movement possibilities stem from their repertoire of "I can's", which are our bodily abilities, both developed and potential. Kinetic joy rides can emerge when the players' elements of their equilibrium are reshuffled enough to open up novel movement potentialities for them to interpret new bodily possibilities. Through the mechanics crafting movement-based games, players exert their movement possibilities and explore new ones. Restraints are part of crafting such mechanics.

\subsection{Bodily Experience in Human-Technology Relations}

Because we are dealing with digital design, the last theoretical concept to introduce is Ihde's [35] embodiment relations as part of his post-phenomenological human-technology relations theory. In his book Bodies in Technology [35], he argues how bodily perception and action are reduced in virtual experiences as compared to non-virtual experiences. He explains that because virtual experiences (herein computer game experiences) build on the audio-visual media tradition, auditory and visual sensory stimulation is emphasised at the expense of bodily actions and movements [35]. Rosenberger and Verbeek [61] referr to Ihde [34] and sum up these points into a magnification/reduction structure: By reducing one sense, another sense "takes over" or by reducing some movement possibilities, other possibilities emerge. As we argue in this paper, restraints in digital design can exploit this structure and affect bodily perception and movement either by sensory deprivation or manipulation or by offering fewer options for full-body actions as compared to non-virtual experiences. We demonstrate such kind of applications in the following examples of digital game designs.

To summarise the theoretical perspectives in this section, we examined the experiential dynamics of restraints as constituting bodily play experiences by reshuffling the elements of our equilibrium [49] and possibly constituting a new space of bodily possibilities [63] from the emerging potentialities [59]. In this process, restraints can, in the form of arbitrarily chosen and unnecessary obstacles to overcome [11,75] stimulate bodily arousal [39] and enable kinetic joy rides [66,67]. Digital technologies offer ways to implement and exploit the use of restraints in the inherent structure of magnifying/reducing bodily perception and action [34,35,61].

With this final theoretical transition into the technological realm, we move on to apply these theoretical perspectives and exemplify how restraints can work with interactive technology. We do so in the following five digital game examples. Based on these examples below and the non-digital movement-based games in section 4, we extract five practical design strategies in section 7 as inspiration for design work with restraints in movement-based games and digital bodily play experiences. 


\section{EXAMPLES OF RESTRAINTS IN DIGITAL DESIGN}

In this section, we implement the theoretical understanding of restraints outlined above as a framework to understand how restraints craft movement-based games and encourage bodily play in five different digital game examples.

\subsection{Inferno: Restraining the Body with an Exoskeleton}

Inferno [14,50] (figure 2) is a live performance of sound, light, and dancing exoskeletons. It was created by performance

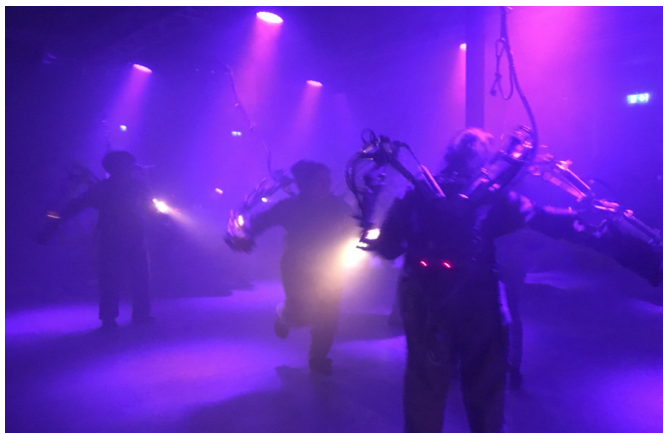

Figure 2: Controlled by an exoskeleton on the upper body, the participants explore and create new bodily possibilities in Inferno.

artists Louis-Philippe Demers [14] and Bill Vorn [81]. The participants are dressed up in an exoskeleton controlling their upper body, while the lower body is free for them to move as they like (figure 2). They can also turn and twist in a circle of approximately three meters in diameter (limited by the cords to the hydraulic system dropped from the ceiling). The exoskeletons are controlled live by a choreographer.

Theoretical analysis of Inferno: The exoskeleton works as a fixation restraint, fixating the participants' upper bodies and taking over the control of their upper body movement. Because they are free to move their lower body parts as they like, this experience reshuffles the elements of their equilibrium. While managing to move around with parts of their movement possibilities controlled externally, their available movement space is changed, revealing a new space of bodily potentialities and new movement sequences to explore and create. In the process of reverting back to equilibrium, the participants are bodily aroused (also stimulated by the loud, rhythmic music, dystopian lightning, and theatre smoke) by the kinetic joy ride of composing movement sequences through the upper body parts restrained by the exoskeleton in combination with the movements in their lower body parts, which they manage themselves.

In this example, the primary mechanic for bodily play is the fixation restraint imposed by the exoskeleton creating the arbitrarily chosen obstacle of dancing partly controlled by an exoskeleton. As such, this technology reduces the participants' bodily perception by only applying only the technology to their upper body parts. The bodily play experience emerges from this reduction when the participants seek to complete this experience into a full-body experience through the rest of the body, which is left for the participants to perceptually stimulate themselves. By adding bodily actions and combining the different movements into full-body movement sequences, the participants kickstart the experiential process of kinetic joy rides.

\subsection{Johann Sebastian Joust: Fixating the Hand with the Move Controller}

Johann Sebastian Joust (JSJ) [17] is a no-graphics multiplayer game created by the prize-winning game studio, Die Gute Fabrik [17] based on the music of J.S. Bach. To play the game, players use PlayStation move controllers, and each player has a move controller. The gameplay is as follows: "When the music [...] plays in slow-motion, the controllers are very 
sensitive to movement. When the music speeds up, the threshold becomes less strict, giving the players a small window to dash at their opponents. If your controller is ever moved beyond the allowable threshold, you're out! "[17]. Each player has a move controller.

Theoretical analysis of JSJ: The restraint in JSJ involves fixating one hand through the controller (the player has to hold the controller as steady as possible), thereby changing the players' bodily preconditions for moving around while playing the game. This situation reshuffles the elements of the players' equilibrium and forces them to explore new movement possibilities. In combination with the endeavours of protecting their move controllers from the other players, the players become bodily aroused and, as a consequence of the new derived movement sequences, can experience kinetic joy rides. Moreover, when the rhythm changes - and with it the controller's threshold for movement and thus that of the fixated hand - the player's (new) preconditions for movement are changed again, temporarily. As such, these restraints are also instances of temporary restraints. When the rules of handling the controller changes - the rules of the restraint changes (though the restraint type remains the same) and the movements required to handle the new situation need to be altered, thereby commencing the process of reshuffling the equilibrium and forming a new space of movement possibilities anew.

In terms of how technology reduces bodily perception, the move controller and music stimulate only the players' hearing sense combined with the movements of the hand holding the controller; the players' other bodily actions complete the rest of the full-body experience. Similar to the Inferno example discussed above, the players complete the bodily experience reduced by the technology into a full-body experience by adding bodily actions and movements through their endeavours encouraged by the gameplay.

\subsection{Fru Game: Fixating Body Parts to Reveal a Hidden Layer}

Fru [79] is a 2D platformer game utilising the Kinect for the Xbox One [93], by the award-winning game studio Through Games [79]. In Fru, the player helps the little avatar through to the other end of the level. The player's silhouette becomes a "portal" between two worlds (figure 3) to move the avatar through the level: When the player moves in front of the Kinect, the player's silhouette reveals another "world" or layer of the platform for the avatar to move around in. The combination of these two worlds forms a pathway for the avatar to reach the other end of the level and advance to a new level.

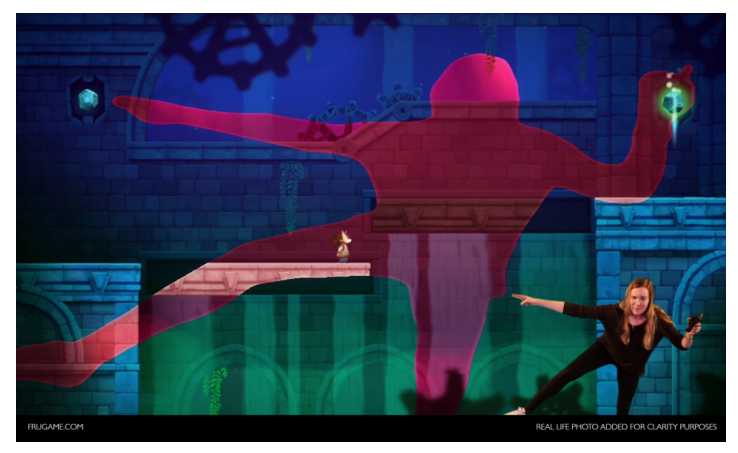

Figure 3 A player playing Fru Game standing on one leg and the right straight to the right. Photo by Through Games.

Theoretical analysis of Fru Game: The restraints in Fru [79] are also fixations, just as in JSJ [17] discussed above, but differently implemented. While a device infers the fixation in JSJ [17], the restraints in Fru [79] are implied directly 
in the interface: The player must stay fixated in the chosen bodily positions to keep the portal to the "other" world open for the avatar to enter and exit this other layer. In these endeavours to keep the other "world" open with their physical body and steer the avatar around using the controller, the player is forced to explore a new and undefined space of bodily possibilities (figure 3), which reshuffles their equilibrium and creates bodily arousal resulting in kinetic joy rides.

While the Fru [79] game is arguably a (quasi) full-body experience, in that besides stimulating the visual and auditory senses, full-body actions are required, neither the tactile sense (apart from handling the controller in one hand) nor the smell or taste senses are stimulated, still reducing bodily perception. In the reduction/magnification structure, this reduction can increase (magnify) the focus on the senses that are stimulated in the experience; coordinating bodily movements and positions with the visual stimuli from the screen to move the avatar through the levels. The player can use the bodily perceptual resources that are not stimulated by the technology (or set in the background of perception [43]) on the senses that are stimulated by the technology and thus magnify the bodily perception of these stimuli.

\subsection{Space Agent: Depriving Bodily Senses to Alter Player Perception and Movement Potential}

Space Agent (SA) [73] is a pervasive sound- and movement-based game utilising binaural audio technology to create a virtual 3D sound space layered on the physical world. In short, the players capture invisible but audible aliens with their smartphone as the weapon. The players seek out the aliens by moving around the cityscape listening to their "Detector" (the smartphone). Besides hunting the aliens on their way around the cityscape, the players can encounter spaceships

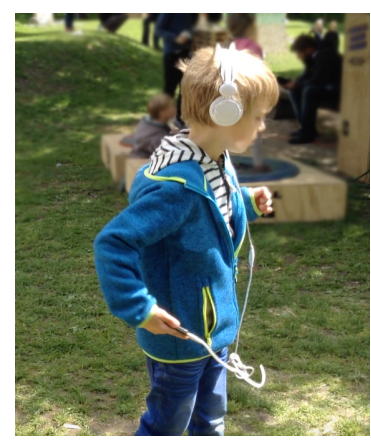

Figure 4: A player with eyes closed catching invisible aliens in Space Agent.

and alien boss monsters or discover the aliens hiding places. Space Agent was created by the game studio Hybrid Play and Games ApS for Space on Earth ApS [73].

Theoretical analysis of Space Agent: The restraint in Space Agent [73] is using technology, to deprive the visual sense and manipulate the hearing sense [37]. In the magnification/reduction structure of embodiment in humantechnology relations, removing visual feedback and manipulating audio feedback through binaural audio, forces the players to use their hearing sense for interactions (figure 4). The players respond and move around according to a 3D soundscape. This way of "blindfolding" the players to navigate the physical surroundings with only audible feedback affects the players' bodily senses, reshuffles their equilibrium and converts bodily arousal into possible kinetic joy rides. By omitting visual feedback (also explored in [72]), the visual sense is reduced (while playing the game) making way for 
other senses to take over - in this game, the hearing sense. In combination with manipulating ${ }^{3}$ the hearing sense through binaural audio and making bodily movements with the smartphone, a new space of bodily movement potentialities emerges; twisting and turning to follow the sound to capture or escape the attacking invisible aliens. Similar to the Fru [79] game, the reduction in one sense frees up bodily resources to use the sense that is stimulated. While this example is an example of how the reduction/magnification structure in bodily perceptual experiences in and of technology is a source for inferring restraints, it also points to how restraints and the use of technology can channel the players' perceptual focus onto different senses.

\subsection{The Move Maker: Exploring Different Combinations of Restraints}

The award-winning game The Move Maker [47] is a bodily play system that forms a new space of bodily potentialities through a range of minigames with different combinations of restraints. The system comprises of a set of body cards with different restraints (covering the three types of restraints presented in section 4) and a range of physical game elements: a moving robot controlled by proximity sensors, a set of light cubes that switch colour when turned, a set of laser pointer lines that when broken raise an alarm with a beeping sound, and, lastly, a set of music cubes that need to be continuously activated to keep playing music. The system contains various minigames, all comprising the same kind of setup, interacting with the game elements while being bodily restrained. An example is moving the robot around a

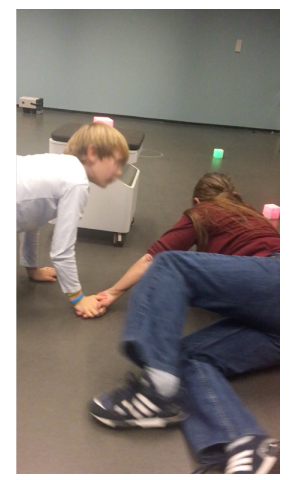

Figure 5: A woman and a boy playing "get through the laser field" while adhering to the restraints from the cards.

maze of light cubes while adhering to the restraint on a card: "your right foot is glued to the ground" (fixation restraint) or "you are not allowed to use your left arm" (exclusion restraint). Another example is to traverse the laser field while being restrained by the body cards. The cards can also be combined into combinations of restraints, e.g., "you are not allowed to use your left arm" together with "your right foot heel is glued to your left knee" in any game.

Theoretical analysis of Move Maker: The obstacles formed by the restraints from the body cards in combination with the challenges of navigating around the game elements in different setups create a range of arbitrary bodily potentialities for the players to interpret into bodily possibilities. In figure 5, the two players try to move through the laser field of differently positioned laser lines; while the woman is not allowed to use her left hand, the boy's knees are glued to the floor, and they have to hold hands. Adhering to the restraints and the position of the laser lines, the players will have to find a way to pass the laser lines. The combination of restraints and motion in the game set-up (here, laser lines), creates arbitrarily chosen and unnecessary obstacles that, in their attempts to overcome them, force the players

\footnotetext{
${ }^{3}$ not augmenting; which is when information from one sense is also distributed to other senses [40].
} 
to search for movement potentialities and create a new space of bodily possibilities. The restraints applied in this example are combinations of exclusion (the woman's hand) and fixation restraints (the boy's knees). The action of holding hands also acts as a fixation for both players' hands (here, left and right hand, respectively). As in the previous examples, this process of overcoming the obstacles (created by the restraints) reshuffles the elements of the players' equilibrium and transforms a sequence of new movements into kinetic joy rides.

Contrary to the previous four game examples using interactive technologies, the restraints in the Move Maker [47] are not instated by digital technologies but by rules from the cards. The interactive elements in the Move Maker [47] are relatively simple, and bodily perception is reduced substantially when interacting with each. However, they work in synergy; the music cubes stimulate auditory sense, the light cubes stimulate the visual and tactile senses, the robot stimulates the kinaesthetic sense and the laser lines stimulate auditory, visual and spatial senses. While the elements in the Move Maker [47] do not directly instate restraints, they complement the restraints as sense stimulation through interactive options. Because players can combine the elements in different ways, the players experiment with reducing/magnifying bodily perception and, thus, the focus on different bodily senses during gameplay. Contrary to the other four examples, the restraints in the Move Maker [47] are instated by rules (from the cards - and not digital technology) that are upheld by the players themselves, which makes the rules easily altered and adjusted to fit the activities. We continue this discussion of rules and restraints in the following section.

\subsection{Restraints and Rules}

As we previously mentioned, restraints are also rule-based. However, rules in games can be upheld differently: In nondigital games, rules are upheld by either by the other players or a referee, while in digital games rules are often upheld by the technology. In digital games, the basic rules are, most often, upheld by the digital system and determined by the interactional parameters defined by the designers, as in JSJ [17] (section 6.2). In JSJ, the move controller upholds the restraint: If players do not comply with the interaction "rules" of not exceeding the movement threshold measured by the controller, they are out of the game. As such, the rules are fixed and unalterable [48], which becomes quite apparent in the Fru game [79] (section 6.3) and Space Agent [73] (section 6.4) examples; here, the rules of interaction are not alterable by the players unless they reprogram the system. However, designers can take advantage of the qualities of interactive devices and implement dynamic changes to the quality of the restraint, as in the JSJ [17] example, where the move controller changes the threshold for movement based on the music.

There are also instances in digital games where rules can be negotiated or altered by the players: Designers can design for "broken" rules [83] or incomplete structures [48] where the players can either alter or add rules that affect the gameplay and the restraints: In JSJ [17] (section 6.2), players can invent rules to fit the game session, e.g., no pushing, only pulling. The Move Maker [47] is also built upon alterable rules, in that the basic ruleset encourages players to negotiate the amount of restraints and agree upon the position of the elements. This way, the players can switch and replace restraints and design the physical play space as they wish and complete the structure of the game. Moreover, in the Inferno example, there were no other rules other than the movement "rules" imposed by the exoskeleton; the rest of the gameplay was determined by the participants to determine. This instance of few rules is an incomplete structure [48] in which the players complete the structure during gameplay by playing either free-form, following the other players, holding dance contest, etc.

In this section, we explained how rules uphold restraints in different ways. In the following section, we describe five different strategies to inspire working with restraints. 


\section{DESIGN STRATEGIES TO APPLY RESTRAINTS AS A BODILY PLAY MECHANIC}

In our work with the different restraint types and subsequent examples, we identified five dominating strategies of using restraints for bodily play: as Bodily Puzzles, Bodily Arousal, restraints as a Core Game Mechanic, as an Interaction Modality, and a way Altered or Augmented Bodily Perception of the Physical Environment. The strategies are provided here for inspiration for working with restraints. While the strategies undoubtedly differ, common to all five strategies is that restraints function to create bodily obstacles [11,75] with the possibility of reshuffling the players' equilibrium [49], creating a potential for kinetic joy rides [66,67]. However, they do so in different ways, emphasising different aspects of the bodily play experience. We elaborate further on each of these below.

While the strategies presented below are meant as an inspiration for working with restraints, the notion of restraints is developed as a generative design resource based on the principles of fixating or excluding body parts or depriving/manipulating bodily senses. Designers can use these principles to develop game mechanics or to explore the effect of technology on the experience of bodily movement and movement possibilities in different ways.

\subsection{Design Strategy 1: Creating Bodily Puzzles through Restraints}

Bodily puzzles are situations in which players have to solve a given movement challenge. Schell explains puzzles in games as "fun problems" that "make the player stop and think" [64] and question: How do I do this? [21]. Bodily puzzles are bodily challenges that force players to seek out different movement possibilities to solve the challenge. In other words, restraints can force players to seek out and convert new movement potentialities [59] into movement possibilities [63]. Examples of bodily puzzles are the Move Maker [47] illustrated in figure 5 - "the two players try to pass the laser field while the woman is not allowed to use her left hand, and the boy's knees are glued to the floor" - and the JSJ [17] explained in section 6.2 - "keep your move controller still while evading the other players' attempts to bounce it off balance and navigate the conditions offered by the room such as chairs, walls, etc." Such situations create bodily puzzles for the players to solve. In the previous examples, such bodily puzzles emerge from restraints in the form of, e.g., the cards' movement challenges in the Move Maker [47] example or by physical "protection" of a device from the other players, as was the case in the Johann Sebastian Joust [17] example. Apart from bodily puzzles, restraints can also create bodily arousal.

\subsection{Design Strategy 2: Creating Bodily Arousal through Restraints}

We learned from phenomenology (section 5) that bodily arousal could emerge as a consequence of reshuffling the elements of the equilibrium by affecting the body's senses. Designers can design for playful bodily arousal by using restraints to target the bodily senses, as in Inferno [50] and Space Agent [73]. In Inferno [50], the designers affected the players' bodily senses by stimulating the kinaesthetic sense through the movements imposed by the exoskeleton [38], while in Space Agent [73], the designers used binaural audio [37] to augment the hearing sense while depriving the visual sense by limiting the use of on-screen cues. Other examples of games that centre around affecting the senses to create bodily arousal are the vertigo games [7-10] mentioned in section 2 and the blind man's buff [82] mentioned in section 4.3. In the game literature, this kind of bodily play is similar to Caillois' [11] Ilinx classification. Ilinx are bodily play activities in which players submit themselves to vertigo as a kind of bodily arousal: "The pleasure is in the disorder

and anxiety the activities infer" [11]. By targeting the body's senses through restraints, designers can design for kinetic joy rides emphasising bodily arousal. 


\subsection{Design Strategy 3: Creating a Game's Core Mechanic through Restraints}

In the examples of hopscotch [92] and JSJ [17], the restraints are a part of the games' core mechanics A core mechanic defines a game's core gameplay [63], and if eliminated, there is no game left, for example, the fixation of the hand by the device in JSJ [17] or the exclusion of players' one foot in hopscotch [92]. Subtracting these elements will finish the game. In the world of traditional movement-based games, using restraints to create a game's core mechanic is quite common. For example, in egg races, players balance an egg while racing; in balloon dance, players dance in pairs holding a balloon between their heads - if players lose their eggs in egg races or balloons in balloon dance, they are out of the game $[53,54]$.

Examples from the digital world in which restraints form a game's core mechanic are vertigo games [7-10] explained in section 2 and Space Agent [73] discussed in section 6.4. In vertigo games [7-10], the core game mechanic that defines the core gameplay is the restraint of manipulating the balance sense using the GVS. In Space Agent [73], the core gameplay is defined by the restraints of manipulating the players' hearing sense through binaural audio and depriving the visual sense by limiting visual feedback. Without these elements, players would be unable to capture any aliens. Whereas, the aliens as an element are replaceable by any other capturable element, such as ghosts, spirits, or other fantasy creatures, still preserving the core bodily gameplay.

In the fourth design strategy, we demonstrate how restraints can function as a game's interaction modality.

\subsection{Design Strategy 4: Using Restraints as Interaction Modality}

The Fru Game [79] example in section 6.3 uses restraints as the game's interaction modality [41]. In this game, the players must fixate body parts (executed through Kinect) to interact with the game interface. This way, the restraint becomes the mode with which the players interact with the game. Interaction modalities refer to the input mode that the user or player uses to communicate with the system through the interface [41]. The Fru game [79] implements the fixation restraint as part of the game interface through which the players communicate with the game system. These appear in the interface as "buttons" that the players must keep "pressed" by fixating a body part onto them. This is different from, e.g., the restraints in Space Agent [73]. While the restraints are implemented through binaural audio and, thus, an interaction modality, the interaction modality in Space Agent [73] is the binaural audio and bodily gestures. In Fru [79], communication with the interface, the input to the game system, is the fixation of body parts.

While this design strategy is the least exploited in the examples demonstrated in this paper, we choose to include it here, as we believe that it is a strategy worth exploring. For instance, in the Move Maker [47] (section 6.5), restraint as an interaction modality can be exploited through the music cubes: If the players had to keep the music activated by fixating a body part in front of the cube and not just by waving it in front of the sensor as a kind of quick button press. In the final design strategy, we exemplify how restraints can be used to alter and augment the bodily perception of the physical environment.

\subsection{Design Strategy 5: Using Restraints to Alter and Augment Bodily Perception of The Physical Environment}

In Space Agent [73] (section 6.4), the designers used binaural audio to create a naturalistic 3D soundscape with invisible aliens. To capture these aliens, the players must twist and turn around the physical environment and move accordingly. This way, the players' space of bodily possibility within the physical environment generates new potentialities for the players to explore. Likewise, the vertigo games [7-10] (section 2) manipulates the balance sense, thereby creating an artificial instability of the physical environment, which the players will try to combat to return to stability - as in 
Merleau-Ponty's [49] explanation of how small deficits in bodily perception reshuffle the players' elements of their equilibrium. These are examples of how to utilise technologies to alter and augment bodily perception through play and thereby offer a different interpretation and understanding of the physical environment and the movement possibilities it offers.

\subsection{A Word of Caution and Opportunity}

A precaution to note when designing with restraints is that because restraints tamper with the players' preconditions for bodily movement as a method of disabling of abilities; not all people may experience this as play, since we all have different bodily skills and abilities - what is easy to deal with and fun to overcome for one person might be perceived as difficult and uncomfortable for another. Returning to our discussion of rules and restraints, a way to design for such differences is to design with "broken" rules [83] or incomplete structures [48]: designs where the players can add, alter, negotiate or subtract rules to accommodate their bodily skill level and abilities. This way, the players avail an opportunity to "even out" different levels in physical abilities.

There is also an opportunity for learning when playing with restraints: By being disabled in different ways, players can experience how it feels to be disabled. Games and play by nature are exploratory and are known to create a special frame and setting (see, e.g., [15,16,39,74]) for experiments with identities and societal issues. Games with restraints can, if designers take caution and pay attention to these issues, lead to a better understanding and possibly empathy for disabled people ${ }^{4}$. An example is how the work with exoskeletons in Inferno also led to research into developing exoskeletons for disabled [38]. Conversely, there is also a risk of the opposite: ridicule or the exposure of disabilities. However, such gameplay would be a dark play activity and not that of "at lege"; mutual consideration to all players' wellbeing leading to a continuous negotiation and alteration of the rules [48]. This paper focuses on the latter.

We believe that restraints as a bodily play mechanic provides a step to advance the field of understanding and designing for bodily play experiences. With these comments, we acknowledge that further research concerning restraints for disabled people is needed. Therefore, we encourage further studies of restraints in a bodily play context for disabled people. Such studies can also discover knowledge for the development of exergames and training apps developed specifically for disabled people and for rehabilitation purposes in general.

\section{DISCUSSION OF RESTRAINTS AND BODILY MOVEMENTS RESULTING IN A REDEFINITION OF RESTRAINTS}

Before concluding this paper, we want to discuss the relationship between restraints, and bodily action and movement. These reflections lead to a redefinition of the initial definition described in section 3 . The redefinition is presented at the end of this section.

Through the theoretical analysis of the examples in section 6, it became obvious that a restraint needs bodily action and movement to work. For example, in Inferno [14,50] (section 6.1), the movement of only the upper body by the exoskeleton without moving the lower body would not yield the same experience of a kinetic joy ride. Likewise, keeping the move controller still in JSJ [17] (section 6.2) without escaping the other players would not start the process of kinetic joy rides, and just listening to the soundscape without reacting to it in Space Agent [73] (section 6.4) would not result in a kinetic joy ride. It is the players' bodily actions and movements in response to the restraint that kickstart the experiences into complete full-body experiences and kinetic joy rides.

\footnotetext{
${ }^{4}$ We use the word disabled in our endeavors to empower this group of people and not the contrary [90]
} 
Regarding this view on the relationship between restraints and bodily movement, we wish to emphasise that restraints are not instructions on how to perform specific movements as we know it from games such as Just Dance [80]. Despite games such as Just Dance [80] "restricting" the players' freedom of movement to specific bodily movements, they do not create a new bodily possibility space, since instructions provide only the possibility for the specified movements. Restraints create a bodily condition that the players have to deal with autonomously in the course of overcoming the unnecessary and arbitrarily chosen obstacles [11,75].

As a final remark, we want to touch upon how and when (almost) any device can function as a restraint when combined with bodily movement. To explain this statement, we use the bicycle as an example. A bicycle, when ridden, forms a restraint; to be able to ride it in any way; there must be at least one body part fixated onto it, to either thread the pedals, steer the handle, or somehow sit on the saddle. Riding it can initiate the process of creating kinetic joy rides by reshuffling the equilibrium, altering the players' space of movement possibilities and creating bodily arousal; as a technology, it reduces bodily action to the movements allowed by the bicycle. As an interactional device into digital systems, the bicycle has already been featured as a game controller [27,87], as a means to run virtual races [88] or as a means to augment bodily capacity [1].

The question then arises that if a bicycle becomes a restraint when ridden, why does a console controller that fixates the players' hands not function as a restraint at any time that the players use it for playing? In our opinion, it does not create an unnecessary or arbitrarily chosen obstacle to overcome with a subsequent altered space of bodily possibilities. Nevertheless, as a device, the controller can be used to create a restraint, as was done with the move controller in the JSJ [17] example (section 6.2) or the smartphone in the Space Agent [73] example (section 6.4). The difference lies in that the players must perceive the role of the controller (or any device) as creating an unnecessary or arbitrarily chosen obstacle in an activity of bodily play [48] and, most importantly, bodily action and movement.

The understanding of restraints presented in this paper is that it is the causal relationship between bodily movement and the restrained interaction with a (digital or non-digital) game system, which forms a range of unnecessary and arbitrarily chosen obstacles. In the attempts to overcome the obstacles, the players constitute a space of altered bodily possibilities encouraging kinetic joy rides. As we have demonstrated in the examples throughout this paper, for a restraint to create arbitrarily chosen and unnecessary obstacles for the players to overcome, the players need to be bodily active and move (hence, the use of the term movement-based games). This last argument leads to a redefinition of the initial working definition of restraints as was presented in section 3:

We define restraints for bodily play as direct fixations or exclusions of body parts, or deprivation or manipulation of bodily senses instated by either rules, actions or the use of devices. When the players move, the restraints constitute unnecessary and arbitrarily chosen obstacles causing a change in the players' bodily preconditions for actions and interactions, which leads to a difference in their bodily movement possibilities. For bodily play experiences, the change in the players' preconditions for actions and interactions starts the process of reshuffling the equilibrium leading to kinetic joy rides.

\section{LIMITATIONS}

In this paper, we have focused strictly on restraints for bodily play without considering restraints from a broader perspective for HCI. While we theoretically ground restraints partially in play and game theory illustrated through games, we acknowledge that restraints as restrictions on bodily freedom of movement might also serve as a resource to advance the studies of bodily experiences in HCI in general. Future research topics in this area might include the application of bodily play mechanics in non-game designs or the effect of various technologies such as wearables on users' preliminary conditions for bodily action and the potential implications for their space of bodily possibilities. 
Finally, we acknowledge that the descriptions, explanations, and theoretical framework presented in this paper only provide a starting point for exploring restrictions on players' bodily preconditions in movement-based games, particularly in HCI. However, we believe that by drawing on and introducing mechanics from the tradition of nondigital movement-based games into the digital movement-based games tradition, we advance one step closer to merging and taking advantage of both worlds.

\section{CONCLUSION}

In this paper, we have developed restraints as a mechanic for bodily play in digital games by building on the familiar mechanic of restricting the players' bodily preconditions for movement based on analysis of a collection of traditional non-digital games. Based on this analysis, restraints were divided into three different types: fixation of body parts, exclusion of body parts, and deprivation or manipulation of bodily senses; these were demonstrated through corresponding examples. Based on the bridging concepts methodology, the further analysis of restraints for bodily play in (digital) movement-based games was based on the theoretical framework of tying together phenomenological theories on bodily experience and movement with theories from play and game studies. Using this theoretical framework, we highlighted how restraints work to infer unnecessary and arbitrarily chosen obstacles for the players to overcome; this may include protecting their move controller in JSJ (section 6.2) or managing to be controlled by an exoskeleton in Inferno (section 6.1). In their (voluntary) attempts to overcome the obstacles, the players' equilibrium elements reshuffle, revealing a new space of bodily possibilities. While managing and exploring the new space of bodily possibilities, the players form sequences of movements merging into kinetic joy rides, which create a potential for bodily arousal. Furthermore, the use of technology for such games leads to a reductions/magnification structure implicating the bodily perceptual experience thereof. This phenomenon can be utilised to instate restraints, which was highlighted in the analysis of the digital game examples in section 6.

From these investigations, we extracted five design strategies for designers to apply in their work (section 7): Bodily Puzzles, Bodily Arousal, A Game's Core Mechanic, Interaction Modality, and Altered or Augmented Bodily Perception of the Physical Environment. The paper ends with a discussion of the role of movement for a restraint to work as a restraint, leading to a redefinition of restraints, different from the initial working definition.

With this work, we aimed to bridge the digital and non-digital body game traditions to provide a piece to the puzzle of understanding and designing for bodily play experiences in HCI. We hope to have provided a generative resource for designers and researchers to advance their work in the field of bodily play and playful movement in HCI.

\section{Acknowledgment}

We want to thank NTNU - Norwegian University of Science and Technology for funding this project.

\section{References}

[1] Josh Andres, Julian de Hoog, and Florian "Floyd" Mueller. 2018. "I had super-powers when eBike riding" Towards Understanding the Design of Integrated Exertion. In The Annual Symposium on Computer-Human Interaction in Play Extended Abstracts - CHI PLAY '18, ACM Press, Melbourne, VIC, Australia, 19-31. DOI:https://doi.org/10.1145/3242671.3242688

[2] Steve Benford, Gabriella Giannachi, Boriana Koleva, and Tom Rodden. 2009. From interaction to trajectories: designing coherent journeys through user experiences. In Proceedings of the 27th international conference on Human factors in computing systems - CHI 09, ACM Press, Boston, MA, USA, 709. DOI:https://doi.org/10.1145/1518701.1518812

[3] Nadia Bianchi-Berthouze. 2013. Understanding the Role of Body Movement in Player Engagement. Human-Computer Interaction 28, 1 (2013), 40-75. DOI:https://doi.org/10.1080/07370024.2012.688468

[4] Boda Borg Cooperation. 2020. Boda Borg. Boda Borg. Retrieved September 8, 2020 from https://www.bodaborg.se/\#intro

[5] Stuart L. Brown and Christopher C. Vaughan. 2009. Play: how it shapes the brain, opens the imagination, and invigorates the soul. Avery, New York. 
[6] Oğuz Turan Buruk and Oğuzhan Özcan. 2018. Extracting Design Guidelines for Wearables and Movement in Tabletop Role-Playing Games via a Research Through Design Process. In Proceedings of the 2018 CHI Conference on Human Factors in Computing Systems - CHI '18, ACM Press, Montreal QC, Canada, 1-13. DOI:https://doi.org/10.1145/3173574.3174087

[7] Richard Byrne. 2015. Vertigo as a Design Resource for Bodily Play. In Proceedings of the 2015 Annual Symposium on Computer-Human Interaction in Play - CHI PLAY '15, ACM Press, London, United Kingdom, 399-402. DOI:https://doi.org/10.1145/2793107.2810280

[8] Richard Byrne, Joe Marshall, and Florian 'Floyd' Mueller. 2016. Designing the Vertigo Experience: Vertigo as a Design Resource for Digital Bodily Play. In Proceedings of the TEI '16: Tenth International Conference on Tangible, Embedded, and Embodied Interaction - TEI '16, ACM Press, Eindhoven, Netherlands, 296-303. DOI:https://doi.org/10.1145/2839462.2839465

[9] Richard Byrne, Joe Marshall, and Florian 'Floyd' Mueller. 2016. Inner disturbance: towards understanding the design of vertigo games through a novel balancing game. In Proceedings of the 28th Australian Conference on Computer-Human Interaction - OzCHI '16, ACM Press, Launceston, Tasmania, Australia, 551-556. DOI:https://doi.org/10.1145/3010915.3010999

[10] Richard Byrne, Joe Marshall, and Florian 'Floyd' Mueller. 2016. Balance Ninja: Towards the Design of Digital Vertigo Games via Galvanic Vestibular Stimulation. In Proceedings of the 2016 Annual Symposium on Computer-Human Interaction in Play - CHI PLAY'16, ACM Press, Austin, Texas, USA, 159-170. DOI:https://doi.org/10.1145/2967934.2968080

[11] Roger Caillois. 2001. Man, Play, and Games. University of Illinois Press.

[12] Mihaly Csikszentmihalyi. 1975. Beyond boredom and anxiety. San Francisco.

[13] Peter Dalsgaard and Christian Dindler. 2014. Between theory and practice: bridging concepts in HCI research. In Proceedings of the 32nd annual ACM conference on Human factors in computing systems - CHI '14, ACM Press, Toronto, Ontario, Canada, 1635-1644. DOI:https://doi.org/10.1145/2556288.2557342

[14] Louis-Philippe Demers. 2015. Inferno. vimeo.com. Retrieved January 24, 2018 from https://vimeo.com/130670526

[15] Sebastian Deterding. 2009. The Game Frame: Systemizing a Goffmanian Approach to Video Game Theory. In (Breaking New Ground: Innovation in Games, Play, Practice and Theory), DiGRA.

[16] Sebastian Deterding. 2017. Alibis for Adult Play: A Goffmanian Account of Escaping Embarrassment in Adult Play. Games and Culture 13, 3 (2017). DOI:https://doi.org/10.1177/1555412017721086

[17] Die Gute Fabrik ApS. 2014. Johann Sebastian Joust Game [Playstation] (11 June 2013). Die Gute Fabrik. Last played 13 October 2018.

[18] Paul Dourish. 2001. Where the action is: the foundations of embodied interaction. MIT Press, Cambridge, Mass.

[19] Sarah Drury. 2016. The Body Image - Body Spatiality in Mobile Augmented Relaity Projects. In L.A.Replay Mobile Network Culture in Placemaking. Leonardo Electronic Almanac, Boston, MA, 140-147.

[20] Henning Eichberg. 2010. Bodily democracy: towards a philosophy of sport for all. Routledge, London.

[21] Henning Eichberg. 2016. Questioning Play: What Play Can Tell Us About Social Life. Routledge, London.

[22] Bill Gaver and John Bowers. 2012. Annotated portfolios. interactions 19, 4 (July 2012), 40. DOI:https://doi.org/10.1145/2212877.2212889

[23] William Gaver. 2012. What should we expect from research through design? In Proceedings of the 2012 ACM annual conference on Human Factors in Computing Systems - CHI '12, ACM Press, Austin, Texas, USA, 937. DOI:https://doi.org/10.1145/2207676.2208538

[24] William W. Gaver. 1991. Technology affordances. In Proceedings of the SIGCHI conference on Human factors in computing systems Reaching through technology - CHI '91, ACM Press, New Orleans, Louisiana, United States, 79-84. DOI:https://doi.org/10.1145/108844.108856

[25] James J. Gibson. 2015. The ecological approach to visual perception. Psychology Press, New York, London.

[26] James G. Greeno. 1994. Gibson's affordances. Psychological Review 101, 2 (1994), 336-342. DOI:https://doi.org/10.1037/0033-295X.101.2.336

[27] Kristoffer Hagen, Konstantinos Chorianopoulos, Alf Inge Wang, Letizia Jaccheri, and Stian Weie. 2016. Gameplay as Exercise. In Proceedings of the 2016 CHI Conference Extended Abstracts on Human Factors in Computing Systems - CHI EA '16, ACM Press, San Jose, California, USA, $1872-1878$. DOI:https://doi.org/10.1145/2851581.2892515

[28] Rex Hartson. 2003. Cognitive, physical, sensory, and functional affordances in interaction design. Behaviour \& Information Technology 22, 5 (September 2003), 315-338. DOI:https://doi.org/10.1080/01449290310001592587

[29] Hasbro.com. 2018. Twister. Game [Board game] 1966. Hasbro. Last played 21 October 2020.

[30] Thomas S. Henricks. 2015. Play and the Human Condition. URBANA; CHICAGO; SPRINGFIELD: University of Illinois Press.

[31] Kristina Höök. 2018. Designing with the body: somaesthetic interaction design. The MIT Press, Cambridge, Massachusetts.

[32] Johan Huizinga. 2016. Homo Ludens, a Study of the Play-Element in Culture. Angelico Press, Kettering, OH.

[33] E. Husserl. 1982. Ideas pertaining to a pure phenomenology and to a phenomenological philosophy (Edmund Husserl collected works; 3). Dordrecht: Kluwer.

[34] Don Ihde. 1990. Technology and the lifeworld: from garden to earth. Indiana University Press, Bloomington.

[35] Don Ihde. 2002. Bodies in technology. University of Minnesota Press, Minneapolis.

[36] Katherine Isbister, Elena Márquez Segura, Suzanne Kirkpatrick, Xiaofeng Chen, Syed Salahuddin, Gang Cao, and Raybit Tang. 2016. Yamove! A Movement Synchrony Game That Choreographs Social Interaction. Human Technology 12, 1 (2016), 74-102. DOI:https://doi.org/10.17011/ht/urn.201605192621

[37] Stefan J. Kasian \& James D. Lane. 1997. Binaural Auditory Beats Affect Vigilance Performance and Mood. Physiology \& Behavior, Elsevier Science Inc. 63, 2 (1997), 249-252. 
[38] Elizabeth Jochum, Louis-Philippe Demers, and Evgenios Vlachos. 2018. Becoming Cyborg: Interdisciplinary Approaches for Exoskeleton Research. 1-9. DOI:https://doi.org/10.14236/ewic/EVAC18.40

[39] J. H. Kerr and Michael J. Apter. 1991. Adult play: a reversal theory approach. Swets \&amp; Zeitlinger, Amsterdam.

[40] Kai Kunze and Stephan Lukosch. 2019. Superhuman sports --- a testing ground for augmenting our senses. XRDS 25, 4 (July 2019 ), $38-43$. DOI:https://doi.org/10.1145/3331069

[41] Masaaki Kurosu and HCI International (Eds.). 2013. Interaction modalities and techniques. Springer, Berlin.

[42] Nicole Lazzaro. 2008. The Four Fun Keys. In Game Usability (1st ed.), Katherine Isbister and Noah Schaffer (eds.).

[43] Drew Leder. 1990. The absent body. University of Chicago Press, Chicago.

[44] Lian Loke and Toni Robertson. 2013. Moving and Making Strange: An Embodied Approach to Movement-Based Interaction Design. ACM Transactions on Computer-Human Interaction 20, 1 (2013). DOI:http://dx.doi.org/10.1145/2442106.2442113

[45] E. J. Lyons. 2015. Cultivating Engagement and Enjoyment in Exergames Using Feedback, Challenge, and Rewards. Games for Health fournal: Research, Development, and Clinical Applications 4, 1 (2015)

[46] Elena Márquez Segura, Annika Waern, Jin Moen, and Carolina Johansson. 2013. The design space of body games: technological, physical, and social design. In Proceedings of the SIGCHI Conference on Human Factors in Computing Systems - CHI '13, ACM Press, Paris, France, 3365. DOI:https://doi.org/10.1145/2470654.2466461

[47] Louise Petersen Matjeka. 2020. The Move Maker - Exploring Bodily Preconditions and Surrounding Conditions for Bodily Interactive Play. In Proceedings of the 2020 CHI Conference Extended Abstracts on Human Factors in Computing Systems, ACM Press, Honolulu, Hawai'i. DOI:https://doi.org/DOI: https://doi.org/10.1145/3334480.3381652

[48] Louise Petersen Matjeka and Florian 'Floyd' Mueller. 2020. Designing for Bodily Play Experiences Based on Danish Linguistic Connotations of "Playing a Game." In Proceedings of International Conference on Human Computer Interaction and Play CHI PLAY, ACM, Online. DOI:https://doi.org/10.1145.3410404/3414264

[49] Maurice Merleau-Ponty. 2012. Phenomenology of perception. Routledge, Abingdon England; New York.

[50] metamorf. 2017. Inferno. meta.morf. Retrieved from http://metamorf.no/2018/project/inferno-louis-philippe-demers-bill-vorn/index.html

[51] Jin Moen. 2005. Towards people based movement interaction and kinaesthetic interaction experiences. In Proceedings of the 4th decennial conference on Critical computing between sense and sensibility - CC '05, ACM Press, Aarhus, Denmark, 121. DOI:https://doi.org/10.1145/1094562.1094579

[52] Jin Moen. 2006. KinAesthetic Movement Interaction Designing for the Pleasure of Motion. KTH, Stockholm. Retrieved January 11, 2021 from http://urn.kb.se/resolve?urn=urn:nbn:se:kth:diva-608 urn:nbn:se:kth:diva-608

[53] Jørn Møller. 2000. Euroleg, 121 gamle lege og spil fra Idraetshistorisk Vaerksteds internationale legepark. Bavnebanke, Idraetshistorisk Vaerksted, Denmark, Slagelse.

[54] Jørn Møller. 2010. Med leg skal land bygges. Bavnebanke, Slagelse.

[55] Florian 'Floyd' Mueller, Richard Byrne, Josh Andres, and Rakesh Patibanda. 2018. Experiencing the Body as Play. In Proceedings of the 2018 CHI Conference on Human Factors in Computing Systems - CHI '18, ACM Press, Montreal QC, Canada, 1-13. DOI:https://doi.org/10.1145/3173574.3173784

[56] Florian 'Floyd' Mueller, Tuomas Kari, Zhuying Li, Yan Wang, Yash Dhanpal Mehta, Josh Andres, Jonathan Marquez, and Rakesh Patibanda. 2020. Towards Designing Bodily Integrated Play. In Proceedings of the Fourteenth International Conference on Tangible, Embedded, and Embodied Interaction, ACM, Sydney NSW Australia, 207-218. DOI:https://doi.org/10.1145/3374920.3374931

[57] Florian 'Floyd' Mueller, Rakesh Patibanda, Richard Byrne, Zhuying Li, Yan Wang, Josh Andres, Xiang Li, Jonathan Marquez, Stefan Greuter, Jonathan Duckworth, and Joe Marshall. 2021. Limited control over the body as intriguing play design resource. In CHI '21: Proceedings of the 2021 CHI Conference on Human Factors in Computing Systems, ACM Press, Online. DOI:https://doi.org/10.1145/3411764.3445744

[58] Florian 'Floyd' Mueller and Katherine Isbister. 2014. Movement-based game guidelines. In Proceedings of the 32nd annual ACM conference on Human factors in computing systems - CHI '14, ACM Press, Toronto, Ontario, Canada, 2191-2200. DOI:https://doi.org/10.1145/2556288.2557163

[59] Alva Noë. 2006. Action in perception (1. MIT Press paperback ed ed.). MIT Press, Cambridge, Mass.

[60] Donald A. Norman. 2013. The design of everyday things (Rev. and exp. ed. ed.). Basic Books, New York.

[61] Robert Rosenberger and Peter-Paul Verbeek (Eds.). 2015. Postphenomenological investigations: essays on human-technology relations. Lexington Books, Lanham.

[62] Asreen Rostami, Donald McMillan, Elena Márquez Segura, Chiara Rossito, and Louise Barkhuus. 2017. Bio-Sensed and Embodied Participation in Interactive Performance. In Proceedings of the Tenth International Conference on Tangible, Embedded, and Embodied Interaction - TEI '17, ACM Press, Yokohama, Japan, 197-208. DOI:https://doi.org/10.1145/3024969.3024998

[63] Katie Salen and Eric Zimmerman. 2004. Rules of play: game design fundamentals. MIT Press, Cambridge, Mass.

[64] Jesse Schell. 2019. The art of game design: a book of lenses (Third edition ed.). Taylor \& Francis, a CRC title, part of the Taylor \& Francis imprint, a member of the Taylor \& Francis Group, the academic division of T\&F Informa, plc, Boca Raton

[65] Helen Sharp. 2007. Interaction design : beyond human-computer interaction (2nd ed. ed.). John Wiley, Chichester.

[66] M. Sheets-Johnstone. 2003. Thinking in Movement. fournal of Aesthetics and Art Criticism 39, 4 (2003), $399-407$.

[67] M. Sheets-Johnstone. 2013. Movement as a Way of Knowing. Scholarpedia 8, (2013), 30375. DOI:https://doi.org/doi::10.4249/scholarpedia.30375

[68] M. Sheets-Johnstone. 2014. Putting Movement Into Your Life: a beyond fitness primer. CreateSpace Independent Publishing Platform.

[69] Maxine Sheets-Johnstone. 2007. Kinesthetic Memory. Theoria et Historia Scientiarum 7, 1 (2007). DOI:https://doi.org/10.12775/ths.2003.005 
[70] Miguel Sicart. 2008. Defining Game Mechanics. Game Studies -the International fournal of Computer Games Research 8, 2 (2008).

[71] Miguel Sicart. 2014. Play Matters. Cambridge, Massachusetts; London, England: The MIT Press.

[72] Iris Soute, Panos Markopoulos, and Remco Magielse. 2010. Head Up Games: combining the best of both worlds by merging traditional and digital play. Pers Ubiquit Comput 14, 5 (July 2010), 435-444. DOI:https://doi.org/10.1007/s00779-009-0265-0

[73] Space on Earth ApS. 2015. Space Agent. Game [IOS, Android] (5 August 2015). Hybrid Play and Games II ApS. Last played 30 November 2016.

[74] J. Stenros. 2012. In Defence of a Magic Circle: The Social and Mental Boundaries of Play. In Proceedings of DiGRA Nordic 2012 Conference: Local and Global - Games in Culture and Society.

[75] Bernard Suits. 1978. The Grasshopper: Games, Life and Utopia. Broadview Press, Canada.

[76] Brian Sutton-Smith. 1997. The ambiguity of play. Harvard University Press, Cambridge, Mass.

[77] Dag Svanæs and Louise Barkhuus. 2020. The Designer's Body as Resource in Design: Exploring Combinations of Point-of-view and Tense. In Proceedings of the 2020 CHI Conference on Human Factors in Computing Systems, ACM, Honolulu HI USA, 1-13. DOI:https://doi.org/10.1145/3313831.3376430

[78] Paul Tennent, Joe Marshall, Vasiliki Tsaknaki, Charles Windlin, Kristina Höök, and Miguel Alfaras. 2020. Soma Design and Sensory Misalignment. In CHI '20: Proceedings of the 2020 CHI Conference on Human Factors in Computing Systems, ACM, Honolulu, Hawaii, USA. DOI:http://dx.doi.org/10.1145/3313831.3376812

[79] Through Games. 2018. Fru. Game [XBOX] (13 July 2016) THrough Games. Last played 20 May 2018

[80] Ubisoft. 2018. Just Dance 2019. Game [SNES, IOS, Android] (17 November 2009). Ubisoft. Last played 21 January 2020.

[81] Bill Vorn. Inferno. http://billvorn.concordia.ca. Retrieved from http://billvorn.concordia.ca/robography/Inferno.html

[82] wikipedia. com. 2018. Blind Man's Buff. Retrieved from https://en.wikipedia.org/wiki/Blind_man\%27s_buff

[83] Douglas Wilson. 2011. Brutally Unfair Tactics Totally OK Now:On Self-Effacing Games and Unachievements. Game Studies -the International fournal of Computer Games Research 1/2011, 11 (2011).

[84] Woco Film. 2011. Blindebuk. Retrieved from https://www.youtube.com/watch?v=zyaJhVlWDRo

[85] 2011. Hinke med hinkesten. Ud at lege som før. Retrieved April 21, 2020 from http://gamlelege.mediajungle.dk/2011/06/02/hinke-med-hinkesten/

[86] 2018. Oxford English Dictionary. Oxford Dictionaries. Retrieved from https://www.lexico.com/definition/restraint

[87] 2018. Playpulse. Playpulse AS. Retrieved May 21, 2018 from http://playpulse.no

[88] 2019. VIRTUAL RACING IN YOUR OWN FRONT ROOM. eurobike.com. Retrieved August 24, 2020 from https://www.eurobike.com/en/topics/sportperformance/virtual-cycling/

[89] 2020. Welcome to the Ancient Olympic Games. Olympic.org. Retrieved July 30, 2020 from https://www.olympic.org/ancient-olympic-games/thesports-events

[90] 2020. \#SAYTHEWORD - THE POWER OF LANGUAGE FOR DISABILITY IDENTITY. Disabled Spector. Retrieved July 5, 2020 from https://disabledspectator.com/saytheword-power-language-disability/

[91] Gerlev Legepark. Gerlev Legepark. Retrieved June 27, 2020 from https://gerlevlegepark.dk

[92] Hopscotch. Wikipedia. Retrieved April 21, 2020 from https://en.wikipedia.org/wiki/Hopscotch

[93] XBOX ONE. Microsoft. Retrieved from https://www.xbox.com/da-DK/games/xbox-one 